\title{
ROLE OF ECONOMY AS SOCIAL INSTITUTION IN CHOLISTAN DESERT
}

\author{
Aisha Shoukat a, Muhammad Jafar a, Inam Ullah Wattoo ${ }^{\text {b }}$ \\ a Department of Social Work, The Islamia University of Bahawalpur, Bahawalpur, Pakistan \\ ${ }^{b}$ Department of Social \& Allied Sciences, Cholistan University of Veterinary \& Animal Sciences, Bahawalpur, Pakistan
}

\section{ARTICLE INFO}

\section{Article history}

Received: September 29, 2021

Revised: November 17, 2021

Accepted: December 21, 2021

\section{Keywords}

Nomadic lifestyle

Economic activities

Animal husbandry

Cholistan

\section{ABSTRACT}

Cholistan is the second largest desert of Pakistan with semi-nomadic culture. Based on its landscape, Cholistan is divided into two parts, i.e., Greater and Lesser Cholistan. This study review highlights the economic activities of native people of Cholistan, challenges faced by people and ways to improve the economic standard of native people. Due to its rough terrain, Cholistan is hardly accessible from outside except specialized vehicles. The entire Cholistan is the least populated area and the existing population is scattered among sand dunes. Cholistan is deprived of socio-economic development and hence there is a lack of basic amenities of life such as drinking water, food, education, healthcare and housing. Due to the scarcity of irrigation water and the landscape of Cholistan, there is hardly any possibility of agri-farming and production grains for livelihood. Animal herds are a major source of livelihood and sustenance for the people of Cholistan. Local people own larger herds of cows, camels, goats and sheep, which are vital for survival, i.e., food sources and money for purchasing necessities. Cholistani people do not possess formal education and skills and are unable to avail any job opportunity in the formal sector. As a result, Cholistani people are choiceless except to depend upon animal husbandry. All the family members, including women, participate in animal husbandry and other small scale agrifarming for earning a livelihood. Life is simple, and daily needs of local people are very limited, and economic activities are few in Cholistan. Social institution is playing their role to educate the people and fulfilling the economic needs of the Cholistani people.

\footnotetext{
* Email: aishashah1@yahoo.com https://doi.org/10.52223/jei3032113

(C) The Author(s) 2021.

This is an open access article under the CC BY license (http://creativecommons.org/licenses/by/4.0/).
}

\section{INTRODUCTION}

Globally, deserts cover more than one-fifth of the earth covering an area of 33.7 sq. km (National Geographic Society, 2014). Nomads are contributing directly or indirectly for the development of their respective communities by provision of socio-economic services. Commonly, these services include dairy products like meat, milk, butter and leather (Ezeomah, 1990). The Cholistan desert is situated in South Punjab over an area of 26100 sq. km. climatically, it is driest and hottest desert of Pakistan where temperature rises to $50^{\circ} \mathrm{C}$ or higher in the month of June (Malik \& Ali, 2017; Ahmad et al., 2005a). Cholistan is second largest desert of Pakistan, where there is semi-nomadic life style. Due to scorching heat, scarcity of water and ever shifting sand dunes, animal husbandry remains major livelihood source (Afzal and Naqvi, 2004). Cholistan, which was once an economically prosperous and fertility wise lush green area, is now almost deserted piece of land. It has a significant contribution in the form of supplying diary product including milk, meat and wool; however, now its productivity is on decline despite the fact that number of animals has increased, but pastures and fodder are decreasing day by day
(Ali et al., 2009). As being located in Southern Punjab, a poverty-stricken area, Cholistan is home to poor and extremely poor households which are directly dependent on rearing and selling animals. Two major reasons for massive poverty in Cholistan include scarcity of water and fodder for Cholistani people and their herds. Although there are pieces of arable land in the Cholistan but cultivation is quite rare because of lack of irrigation water on a permanent basis. Ground water is deep from the earth's surface and brackish; that is why it is not useable for drinking or irrigation (Afzal \& Rizwan, 2017). As the land of Cholistan is not fit for the cultivation of crops, so Cholistani people have no other option except to raise their livestock on natural flora/pastures. This dependency compels them to adopt and nomadic and semi life style and keep on migrating from one place to another in search of water and grazing sites for their animals (Khan \& Khan, 2015).

Nomads keep on migrating from one location to another even when there is no shortage of water and fodder. This movement provides new avenues for animal herds which are major 
sources of everyday food and dairy products. Certain animals like cows, goats and sheep are milking animals where camels and donkeys are used for transportation from one place to another. Usually, nomads own larger herds of animals because they can sell them anywhere for fulfilling immediate needs of food and other basics of life (Pedersen \& Benjaminsen, 2008). Animal rearing is the main source of livelihood for nomads that is why their whole life revolves around animals and their care. Generally, nomads live in joint family system and move in the group form. The whole family moves from one place to another along with their animal herds for availing next available seasonal pasture (Manderscheid, 2001).

Animals are not only a source of livelihood for nomads but also fulfill their dietary needs. Usually having no permanent assets, nomads own animal herds as their social and economic asset (Aklilu \& Catley, 2009). Larger the herds, higher would be income level and social status of the owner because, in a pastoral economy, animals are the chief source of income. In nomadic culture, animal herds are considered as a security against odds of life because there is no other source for earning as animals. Without increasing herd size to a certain level, individual animals cannot be sold because of economic vulnerability (Aklilu \& Catley, 2009). The nomadic economy is informal and mainly depends upon animal husbandry. Generally, all the family members participate in economic activities directly or indirectly so that survival can be made possible. Because of the lack of educational institutions, nomadic people do not possess formal skills and training, hence unable to catch any job opportunity in formal sector. During the harvesting season of several crops like wheat, rice, maize and cotton, some family members move in nearby settled areas for earning cash or grains, which serve as food sources. Nomadic women also contribute to the family economy by taking care of animal herds and selling dairy products in the nearby settled villages and towns.

The study aims to explore the nature of economic activities in Cholistan desert. Furthermore, it also focuses on the role of women they extend for earning livelihood for the whole family in the challenging environment of Cholistan desert. For achieving stated study objectives, an ethnographic approach was adopted, and data were collected from 50 participants through protracted qualitative interviews. As Saraiki is a local language, so researcher took help of two research assistants who were well versed with the local language as well as culture. Help of a local guide was also sought for reaching the participants scattered in the desert area. The verbatim was transcribed and analyzed through the thematic analysis technique.

\section{Economic Activities in Cholistan}

Cholistan, being desert area has semi-nomadic life style that is why animal husbandry remains key source of income (Akhter \& Arshad, 2006). Traditional economy of nomads depends upon animal herds such as camels, goats, sheep, and reindeer. Herd size is considered as a status symbol and an element of social recognition in the nomadic culture. Nomads sell out their animals for meeting certain needs such as buying food items, arranging birth and marriage ceremonies, getting medical treatment for both human beings and animals, and purchasing ordinary items such as utensils, clothes, and bikes, etc. (Ezeomah, 1990).

In case of Cholistan, chief sources of income include livestock, cultivation, textile industry (hand-woven cloths), and crafts (Dar, 2007). However, for centuries survival of Cholistani people was dependent on animal husbandry. Like nomads in other parts of the world, Cholistani people sell out their animals like goats, cows, sheep, and camels when they need money for buying food items such as wheat, rice and pulses. In addition to it, money earned through animals is also utilized for buying seasonal and occasional clothes. Likewise, this money is also spent on arrangements of social events like marriage or the death of someone in the family. Animals are also slaughtered for meat supply at the time of big social gatherings and meeting the nutritional needs of family members.

In Cholistan, seasonal migration has an important role in the local economy because it is done for finding water and grazing sites for the livestock. When there is no precipitation for a long time, Cholistani people have no choice except to migrate to other sites where there is the availability of water. They would keep on waiting for adequate rainfall until water sources have been re-filled in their respective areas; by then, they return to Greater Cholistan with their animals. However, there is change in migratory patterns as now nomads divide their family members and their animals into two parts. Few working members of the family drive non-milking animals to Greater Cholistan while the rest of the family members take care of milking animals in the Lesser Cholistan so that they get the market price of their dairy product. Cholistani people have adopted a new approach for raising their income, they keep milking animals in the Lesser Cholistan or settled areas where there is road access, so that they can sell dairy products, especially milk at market price. Non-milking animals are kept in Greater Cholistan, where they can graze (Ahmad et al., 2005b). In Greater Cholistan, cultivation does not provide any viable support to household income. Most parts of Greater Cholistan consist of sand dunes and so not fit for the cultivation of common crops. There are patches of land in Cholistan where crops may be grown; however, scarcity of water makes it impossible for Cholistani people whose major concern remains drinking water. Underground water is deep and unfit for maintaining and increasing soil fertility, that is why seasonal rainfall remains a major source of irrigation, and once there is rain, Cholistani people preserve this humidity for the cultivation of mustard, barley wheat and such other crops. These grains are utilized as food sources.

According to the report of PCRWR, the underground water in the desert area is salty and so not fit for cultivation and human as well as livestock drinking (Kahlown, 2007), that is why agricultural activities are not beneficial for Cholistani people and is not considered a viable source of household income. Life in Cholistan revolves around water sources, and its nonavailability is a pushing factor for migration leading to a nomadic lifestyle in Cholistan. Water is stored in tobas and kunds. In the summer season, there is faster evaporation from all open water sources due to high temperatures. It results in acute water scarcity, and local people migrate to the nearby areas in search of water (Kahlown, 2007). In the economy of 
Cholistan, the informal textile industry has also contributed as local people earn some money by selling handmade cloths. There are locally manufactured handlooms and fine clothes are knitted on them. These clothes are sold in the nearby markets at a valuable price. Similarly, in Cholistan, handicrafts are also one of the sources of earning. There is number of handicrafts such as knitting Lungi, Khes, Shaal, Rug and dying Chonri and bed sheets in unique way. Among other handicrafts, Chonri is well known and is given as a gift to the people outside the Cholistan. There are well known families which possess skills of preparing and dying Chonri and are transferred to the next generation. Mostly items are made from sheep, goat and camel wool. There is no proper marketing for these items, so they return only a little money to the Cholistani people. Secondly, due to lack of direct link and access to any market and marketing skills, local people sell their handicrafts at very low rates as compared to market price.

\section{Animal Husbandry}

Economic activities in greater Cholistan revolve majorly around livestock due to its geographic and environmental conditions. Greater Cholistan is characterized by a dearth of water and ever shifting sand dunes. There is no irrigation system is this part of Cholistan and natural resources remain source of survival for the people of Cholistan. In addition to it, so far this area has not been electrified and there is solely dependence on natural resources. Basic infrastructure such as electricity, road and transportation are considered as prerequisites for development of any area and operation of economic activities that is why there are no earning opportunities in the Cholistan except livestock. Economy in the Cholistan is majorly dependent upon herding and grazing. Different desert animals such as camels, sheep and goats serve both purposes, for selling the animal itself or selling its product such as butterfat, wool and skin (Ahmad et al., 2005b).

In Greater Cholistan, economic activities are limited to animal husbandry due to scarcity of water and lack of cultivation. Although many of households have been allotted land but cultivation is not possible due to the non-availability of water except seasonal rains. Human and animal life is dependent upon the availability of water; in the summer season when tobas, and kunds get dry, local people migrate from one place to other in search of water. Sometimes, this migration is within Cholistan area, and some other times it is outside the Cholistan to the nearby settled areas having availability of water. In the desert areas, green grass and other herbs are found only after rainy season. So, for feeding the livestock, local people keep searching for fodder and shift to the grazing spot where they can feed their animals better. Because of scarcity of drinking water and pastures, nomadic population keeps on migrating from one locality to another in both winter and summer seasons. This movement helps them in availing free pastures available in the area (Ezeomah, 1990). One of most important daily tasks of the Cholistani people is grazing their herds over these pastures. Hence nomads make of land by grazing their animals which transform natural pastures into human food. Animals are source of milk, leather, wool and hairs (Spooner, 1973).
In Cholistan, there are two types of animals being raised. First category is of milking animals; their milk is used for domestic needs and secondly selling it for earning some money. In Greater Cholistan, where milk collection centers are far from the living place and daily access is impossible, local people make butterfat and then sell it in the nearby villages and towns. The second category of animals is that which are nonmilking and are sold for cash. Animals that are kept for the production of meat production are further divided into two types. Sometimes local people sell animals for meeting their immediate needs throughout the year. Another type of animal is kept for selling on Eid-ul Azha.

\section{Fragmented Cultivation}

In Greater Cholistan, an increase in household income is largely dependent on rainfall. If there are timely and adequate rains, it results into economic benefits for local people. After rainfall, natural grass grows which serves as fodder for livestock. When better fodder is available to the livestock, then their financial value is increases. Due to lack of irrigation water and few drops of rain, people in the Cholistan preserve moisture in the soil and grow mustard and barley for their own utilization as well as for selling. In case there are timely and continuous rains, there would be no water scarcity and hence no need to move for water and fodder.

However, if there is no rain for a long time and water sources (toba and kund) have dried, then it is compulsory to move in search of water for saving human beings as well as animals. During the migratory period, Cholistani people work as a laborer with the farmers of the settled areas for getting fodder for their animal herds. In the settled areas, animals cannot be set free for grazing like in Cholistan because animals cause harm to the crops of farmers.

\section{Handicrafts}

The informal textile industry is one of the economic activities in greater Cholistan. This is centuries-old skill that is transferred from one generation to the next. There are some known families who have skills in knitting very fine and decent clothes, rugs and a variety of khes on handlooms. Local people process wool for making smooth tread during grazing their animals in the desert. Herders do not have the need to be vigilant for controlling animals within a specific area for grazing animals, so they sit at one place under the shade of tree and prepare thread for knitting clothes, rug and khes. Due to lack of access to and knowledge about market, Cholistani people get minimal financial benefits from it. They sell this cloth to the middle man who takes it in the market and gets much higher price than given to weavers.

\section{Women and Economic Activities}

Women have a variety of roles in maintaining and rising income level of the family in Cholistan. As mentioned earlier, animal rearing is the major source of earning subsistence, so women play a significant role in this field. They go out of home for collecting fodder for the animals. They go for milking the animals and preparation of butterfat. Likewise, responsibilities of women include fetching water from distant places for calves and lambs which cannot move to the pasture 
for grazing. Women also participate in making wooden shades for the animals and taking care of those animals which are kept at home in these shades due to certain reasons. The findings of the study are consistent with Hasan (2018) who stated that recent socio-economic changes have resulted in manyfold increased responsibilities in responsibilities of Cholistani women. Currently, women have to perform not only traditional domestic chores but also marketing and selling of dairy products and handicrafts.

In Cholistan, survival of animal herds is dependent on natural grazing sites because there is an alternate source for feeding them. That is why migration from one area to another becomes inevitable for availing maximum grazing sites. Pastoralism is purely based upon organic pastures and demands for continuous migration as any natural pasture can support for a limited time (Spooner, 1973). During the migration period, all the family members equally participate in preparation of ghopa and caring of animals. With the passage of time, there is change in the economic role of women in the Cholistan. In the past, women churn the milk for preparing butterfat which was sold to the people of the settled area for getting money. At present, this practice has changed; women have to go to sell milk to the milkman or at the nearby milk collection center established by Cholistan Development Authority. Women in group form carry the pot of milk on their heads and go for selling. With this money, edibles of daily use are purchased for the whole family.

During the harvesting season of the wheat, women migrate with some family members to the settled village areas where they can find wheat for harvesting. Per acre labor cost for harvesting wheat is fixed from time to time depending upon the yield. Women arrange for their temporary hut by collecting woods from vicinity. Sometime, all the family members stay under a tree for months during harvesting season. After doing daily domestic chores such as preparing food, women go to the field and harvest the wheat for the rest of the day time. In this way, they get wheat for all family members.

Unlike Greater Cholistan, there are parts of lands that are arable for growing certain grains and fodder. However, due to scarcity of irrigation water, cultivation is subject to rainfall. That is why, animal husbandry remains major economic activity in this part of Cholistan. Women play important role for animal husbandry as they help in collecting fodder from vicinities for milking animals and bringing water from nearby source. Usually, milk is sold out to the milkman, however, sometimes some milk is not sold out, and in such case women would churn it and get butterfat from it which is sold. As compared to Greater Cholistan, there is sedentary life style prevalent in the Lesser Cholistan and so are economic activities. Cholistan Development Authority has completed several schemes for water supply to different areas of Lesser Cholistan that is why landowners are more focusing on cultivation. In sedentary lifestyle, women have to actively participate in economic activities in terms of sowing crops. They have to work for both animal husbandry and cultivating crops. There is also another side of sedentarization, it results into loss of wealth in term of reduction in herd size, and this means men would be out of work and women have to go for extra work (Ibrahim, 1982).
With the advent of new boring technology and the use of solar energy, soil irrigation has become easier than in the past; that is why there is an increasing trend of small-scale cultivation in Lesser Cholistan. The cultivation process in arid and semi-arid areas demands more laborious work than the plain fields. That is why the whole family has to join hands for making the cultivation possible in Cholistan area. Females get up early in the morning and do the daily domestic chores including cleanliness of home and preparation of breakfast. After that, they have to travel for several miles to reach crop fields, usually by donkey/camel carrots or tractor trolley.

In recent years, due to an increase in cultivation areas, pastures have squeezed, resulting in a cut on animal herds. As result of this change, some of the males work as a laborer in agricultural activities. Likewise, women work as laborer for cotton picking and harvesting other crops like maize. Since there are no free grazing sites in the Lesser Cholistan, so herd owners have to either produce their own fodder or have to buy with money. For addressing this problem, herd owners send their non-milking animals to Greater Cholistan for availing free of cost natural pastures for several months. In Cholistan, close relatives and tribesmen extend cooperation with each other and exchange labor work. Under this practice, for certain period, one family would take care of the herds of all the partners, whereas this care is rotated turn by turn. In this way, each of partner can save time and energy for some other purposes (Homewood, 2006).

\section{Challenges for Economic Institution in Cholistan}

An economic institution is facing many challenges in the Cholistan, mainly due to its topography. Major part of Cholistan consists of sandy dunes with varying heights. Shoukat et al. (2020) noted that due to rough terrain and odd climatic conditions, Cholistan had been overlooked by government departments and private developmental agencies alike.

Underground water is with high salinity, therefore large-scale cultivation in the area is not possible. Major source of income is livestock which is also facing many problems due to lack of drinking water and of veterinary health services. Due to illiteracy and lack of access to media, Cholistani people have poor awareness about animal husbandry, including veterinary diseases and hence get minimum income. Above all, lack of negotiation and marketing skills, Cholistani people receive a poor monetary reward for their dairy products. Likewise, women face cultural restrictions for physical mobility and gender discrimination as societal norm (Hasan, 2018). Prevalence of diseases among animals and scarcity of water are two major factors contributing to poor production of livestock; that is why the focus of developmental programmes for livestock in most of the countries is on provision of watering points and eradication of diseases among animals (Ezeomah, 1990). When there are no rains in the Cholistan for long time and all sources of water such as tobas, kunds get dry, it results into drought which causes of death of animals on massive level. Drought causes heavy financial loss to already poor and vulnerable people of Cholistan taking many years to meet the financial loss.

Global warming and other environmental factors have caused a reduction in sporadic average rainfall per year. Decrease in 
precipitation results in frequent droughts in the desert area. Generally, in the Cholistan, from April to August, there is drought like situation which adversely affects the life of people and economic activities in the desert. Major problem in the nomad lifestyle is poor quality of drinking water and insufficiency of fodder which becomes severe in the summer season (Ahmad et al., 2005b). In both parts of Cholistan, there is neither formal industry nor infrastructure needed for providing employment opportunities to the local people. In the absence of all the basic and necessary facilities such as electricity, gas and roads, there is only informal cottage industry as a secondary source of getting money. There is no facility from government or private institutions for skill training and loans. Likewise, due to poor knowledge about marketing handicrafts, Cholistani people earn very little amount of money from these sources. Under these circumstances, there is animal husbandry and informal labor work in agricultural fields for earning subsistence. Consequently, people in Cholistan are leading life full of miseries and helplessness. Major part of the population in Cholistan is still surviving on traditional income sources and failed to make progress. The main reasons behind this stagnation are lack of literacy/education, lack of access for outsiders due to non-availability of road, lack of infrastructure and poor awareness about raining livestock on modern lines. Lack of support from the government as well as private developmental organizations is another reason. As noted by Farooq et al. (2010), although Cholistan is typical rangeland and tropical area, yet it presents amazing combination of biophysical, ecological, socioeconomic and cultural integration. The nomadic and pastoralist population of Cholistan needs the attention of concerned stakeholders for the upgradation of livestock.

\section{Way Forward for Improving Economic Conditions}

Cholistan desert covers a vast area that can be made productive and optimally rewarding for local dwellers. In this regard, integrated agriculture development may play a significant role in uplifting income levels and improvement of living conditions of local people. Use of modern technology for boring and installing tube wells may help to irrigate land which can grow crops. Likewise, solar energy may be used as an alternative to electricity and agricultural activities may be increased by making it used especially for water. Livestock is much profiting activity given that it is carried out on modern lines and maximum output is sought. Cholistani people should raise such breeds which are more productive in term of milk and meat along with tolerating scorching heat of summer season. Government and NGOs should come forward to help herders to learn negotiating and marketing skills so that they may get the maximum price of their products. Last but least, handicraft needs patronage and intervention from government and private welfare agencies for their proper marketing and getting the reasonable price of their products.

\section{CONCLUSIONS}

Cholistan is a desert area of Pakistan, and due to geographic and climatic conditions, it is hardly accessible for outsiders, including government and private developmental agencies; that is why the entire area is lagging behind in socio-economic development and deprived of basic amenities of life. Livestock, including cow, camel, goat, and sheep remains the major source of income in the absence of any other earning opportunity for the people of Cholistan. Agri-farming is possible only in a small part of Cholistan because of the lack of irrigation water and the nature of soil (sand dune). Women of Cholistan are equally contributing to livelihood activities along with their men. Though there are extraordinary conditions in Cholistan, yet economic institution is playing its role in the fulfillment of the needs of the local people. The role of economic institution includes arranging the production of goods and services, their distribution and consumption; this is also applicable in exclusive community like Cholistan. The role of the family economy as a social institution is intertwined and interlinked in the context of Cholistan because of the joint and extended family system prevalent in Cholistan.

\section{REFERENCES}

Afzal, M., Naqvi, A.N., 2004. Livestock resources of Pakistan: Present status and future trends. Quarterly Science Vision 9. Accessed on October 18, 2019 from; http://www.sciencevision.org.pk/BackIssues/Vol9/22.lives tock.pdf.

Afzal, M., Rizwan, M.A., 2017. To assess the trends of living and poverty in a desert climate. Water Conserv. Manag. 1, 15-18.

Ahmad, F., Ali, Z., Farooq, S., 2005a. Historical and archaeological perspectives of soil degradation in Cholistan. Soc. Nat. 1,864870.

Ahmad, F., Gulzar, F., Shirazi, S.A., Farooq, S., Ali, Z., 2005b. Agropastoral systems in Cholistan. Pakistan Geogr. Rev. 60, 65-69.

Akhter, R., Arshad, M., 2006. Arid rangelands in the Cholistan desert (Pakistan). Sci. Chang. planétaires/Sécheresse 17, 210-217.

Aklilu, Y., Catley, A., 2009. Livestock exports from the Horn of Africa: an analysis of benefits by pastoralist wealth group and policy implications. Medford Feinstein Int. Center, Tufts Univ.

Ali, I., Chaudhry, M.S., Farooq, U., 2009. Camel rearing In Cholistan desert of Pakistan. Pak. Vet. J. 29, 85-92.

Dar, S.Z., 2007. Sights in the Sands of Cholistan: Bahawalpur's history and architecture. Oxford University Press, USA.

Ezeomah, C., 1990. Educating Nomads for Self-Actualization and Development. Literacy Lessons. Available at: https://eric.ed.gov/?id=ED321066.

Farooq, U., Samad, H.A., Sher, F., Asim, M., Khan, M.A., 2010. Continuing education article Cholistan and Cholistani breed of cattle. Pak. Vet. J. 30, 2074-7764.

Hasan, R., 2018. Piece work and feminization of informal economy: Case study of Cholistani women. Pakistan J. Gend. Stud. 17, 143-164.

Homewood, K., 2006. As pastoralists settle: Social, health and economic consequences of pastoral sedentarization in Marsabit district, Kenya. Hum. Ecol. 34, 297.

Ibrahim, F.N., 1982. The role of women peasants in the process of desertification in Western Sudan. GeoJournal 6, 25-30.

Kahlown, M.A., 2007. Rainwater Harvesting in Cholistan Desert: A Case Study of Pakistan. PCRWR, Islamabad. Pakistan.

Khan, A.A., Khan, K., 2015. Women's role in livestock economy of Cholistan Desert, Pakistan. Glob. J. Human-Social Sci. E Econ. 15, 29-39. 
Malik, S.M., Ali, A., 2017. Sustainability of subsistence livelihoods of agro-pastoralists in changing socioeconomic environment of Cholistan Desert-Pakistan. Pakistan J. Commer. Soc. Sci. 11, 1100-1133.

Manderscheid, A., 2001. Decline and re-emergence of nomadism: Tibetan pastoralists revive a nomadic way of life and production. GeoJournal 53, 173-182.

National Geographic Society, 2014. National Geographic. (Available online). Accessed on August 02, 2021 from: http://www.nationalgeographic.com/environment/habitats /deserts/.

Pedersen, J., Benjaminsen, T.A., 2008. One leg or two? Food security and pastoralism in the northern Sahel. Hum. Ecol. 36, 43-57.

Shoukat, A., Zafar, S., Jafar, M., 2020. Women Dealing with Health Problems in Desert: A Case Study of Cholistan. Pakistan Perspect. 25, 235-251.

Spooner, B., 1973. The cultural ecology of pastoral nomads. Addison Wesley Publishing Company.

Publisher's note: Science Impact Publishers remain neutral with regard to jurisdictional claims in published maps and institutional affiliations.

Open Access This article is licensed under a Creative Commons Attribution 4.0 International License, which permits use, sharing, adaptation, distribution and reproduction in any medium or format, as long as you give appropriate credit to the original author(s) and the source, provide a link to the Creative Commons license and indicate if changes were made. The images or other third-party material in this article are included in the article's Creative Commons license, unless indicated otherwise in a credit line to the material. If material is not included in the article's Creative Commons license and your intended use is not permitted by statutory regulation or exceeds the permitted use, you will need to obtain permission directly from the copyright holder. To view a copy of this license, visit https://creativecommons.org/licenses/by/4.0/. 